Check for updates

Kent, UK

Cite this as: BMJ 2021;374:n2157 http://dx.doi.org/10.1136/bmj.n2157 Published: 01 September 2021

\section{Long covid: One in seven children may still have symptoms 15 weeks after infection, data show}

\author{
Jacqui Wise
}

A large study of children and young people who caught SARS-CoV-2 has found that as many as one in seven (14\%) may still have symptoms 15 weeks later. ${ }^{1}$ However, this figure is lower than in some studies that have reported a prevalence of long covid as high as $51 \%$ in children and young people.

Speaking at a Science Media Centre briefing, the study's lead author, Terence Stephenson, who is Nuffield professor of child health at the UCL Great Ormond Street Institute of Child Health in London, said, "It is reassuring that the figures were lower than the worst case scenarios predicted last December. However, they are not of trivial importance."

The Children and Young People with Long Covid (Clock) study is published as a preprint and has not yet been peer reviewed. But its strengths are that it is nationally representative, relies on PCR proven covid status, and includes a covid negative comparison control group.

The researchers contacted young people aged 11-17 from the database of test results held by Public Health England from January to March 2021. They sent questionnaires to 220 ooo young people in England and received 17 ooo responses.

This preliminary analysis included 3065 young people who had tested positive for SARS-CoV-2 and a matched cohort of 3739 who had tested negative. Both groups completed detailed questionnaires three months after their test.

The researchers found that 15 weeks after their PCR test $66.5 \%$ of people who had tested positive and $53.3 \%$ of those who had tested negative had one or more symptoms. About $30 \%$ of those who had tested positive for covid-19 had three or more symptoms, compared with $16 \%$ of those who tested negative. This enabled the researchers to conclude that $14 \%$ of people who test positive for covid have persistent symptoms. The most common symptoms reported were headaches and tiredness.

The high numbers of young people who tested negative reporting symptoms at 15 weeks may be explained by tiredness being common in this age group generally and the survey period coinciding with the return of school after lockdown and a likely increase in non-covid infections.

\section{Wellbeing}

Roz Shafran, study coauthor from the UCL Great Ormond Street Institute of Child Health, said, “Our study also shows the importance of having a comparison group so that longlasting covid-19 symptoms are not confused with non-covid-related ill health. Without a control group of young people, our findings would be uninterpretable."
One limitation of the study is that the response rate was only $13.5 \%$. The researchers say that if this $13 \%$ is representative of all 11-17 year olds who have tested positive, 32 ooo throughout England would still have three or more physical symptoms three months later. However, if only teenagers who responded to the survey had any persisting problems and those who chose not to respond had completely recovered, this would mean a best case scenario of 4000 cases of long covid. These figures are over and above the background level of symptoms experienced by the negative test control group.

No difference was found in mental health and wellbeing scores between young people who tested positive and those who tested negative, but a high proportion in both groups reported being a bit or very worried, sad, or unhappy ( $41 \%$ of those who tested positive $v 39 \%$ who tested negative.)

The UK's Joint Committee on Vaccination and Immunisation (JCVI) is currently deciding whether to extend covid vaccination to all young people aged 12-15.

Liz Whittaker, senior clinical lecturer in paediatric infectious diseases and immunology at Imperial College London, told the briefing, "It's unclear at this time whether vaccination will prevent long covid, and the JCVI will be basing their decision on the risk of severe disease and the risk of the vaccine."

Commenting on the study, Nick Bishop, vice president for science and research at the Royal College of Paediatrics and Child Health, said, "This is a carefully designed and conducted piece of work that adds significantly to what we know about the later effects of covid-19 infection in some children and young people and, importantly, the differences found compared to adults."

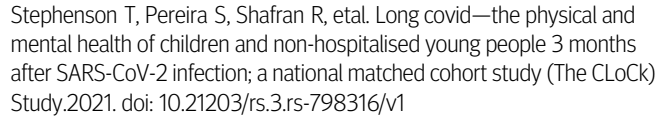
mental health of children and non-hospitalised young people 3 months after SARS-CoV-2 infection; a national matched cohort study (The CLOCk) Study.2021. doi: 10.21203/rs.3.rs-798316/v1

This article is made freely available for use in accordance with BMJ's website terms and conditions for the duration of the covid-19 pandemic or until otherwise determined by BMJ. You may use, download and print the article for any lawful, non-commercial purpose (including text and data mining) provided that all copyright notices and trade marks are retained. 